\title{
Retraction
}

\section{Retracted: Enhancing Energy Efficiency of Wireless Sensor Network through the Design of Energy Efficient Routing Protocol}

\author{
Journal of Sensors \\ Received 20 December 2018; Accepted 20 December 2018; Published 12 March 2019 \\ Copyright (c) 2019 Journal of Sensors. This is an open access article distributed under the Creative Commons Attribution License, \\ which permits unrestricted use, distribution, and reproduction in any medium, provided the original work is properly cited.
}

Journal of Sensors has retracted the article titled "Enhancing Energy Efficiency of Wireless Sensor Network through the Design of Energy Efficient Routing Protocol" [1]. The article was found to contain a substantial amount of material, without citation, from the following published article: Tayseer Al-khdour and Uthman Baroudi, "A Generalised Energy-Efficient Time-Based Communication Protocol for Wireless Sensor Networks," Int. J. of Internet Protocol Technology, 2009 Vol.4, No.2, pp.134-146. doi:10.1504/IJIPT.2009.027338 [2].

The methods and some of the results are the same. For example, the values in Table 2 are the same as those in Table 4 in [2], other than the second digit in each value being different.

\section{References}

[1] N. Zaman, L. Tang Jung, and M. M. Yasin, "Enhancing energy efficiency of wireless sensor network through the design of energy efficient routing protocol," Journal of Sensors, vol. 2016, Article ID 9278701, 16 pages, 2016.

[2] T. A. L. khdour and U. Baroudi, "A generalised energy-efficient time-based communication protocol for wireless sensor networks," International Journal of Internet Protocol Technology, vol. 4, no. 2, pp. 134-146, 2009. 


\title{
Enhancing Energy Efficiency of Wireless Sensor Network through the Design of Energy Efficient Routing Protocol
}

\author{
Noor Zaman, ${ }^{1}$ Low Tang Jung, ${ }^{2}$ and Muhammad Mehboob Yasin ${ }^{1}$ \\ ${ }^{1}$ College of Computer Sciences \& IT, King Faisal University, Al Ahsa 31982, Saudi Arabia \\ ${ }^{2}$ Department of Computer \& Information Sciences, Universiti Teknologi PETRONAS, 32610 Seri Iskandar, Perak, Malaysia \\ Correspondence should be addressed to Noor Zaman; nzaman@kfu.edu.sa
}

Received 25 March 2016; Revised 22 May 2016; Accepted 29 May 2016

Academic Editor: Fei Yu

Copyright (c) 2016 Noor Zaman et al. This is an open access article distributed under the Creative Commons Attribution License, which permits unrestricted use, distribution, and reproduction in any medium, provided the original work is properly cited.

\begin{abstract}
Wireless Sensor Network (WSN) is known to be a highly resource constrained class of network where energy consumption is one of the prime concerns. In this research, a cross layer design methodology was adopted to design an energy efficient routing protocol entitled "Position Responsive Routing Protocol" (PRRP). PRRP is designed to minimize energy consumed in each node by (1) reducing the amount of time in which a sensor node is in an idle listening state and (2) reducing the average communication distance over the network. The performance of the proposed PRRP was critically evaluated in the context of network lifetime, throughput, and energy consumption of the network per individual basis and per data packet basis. The research results were analyzed and benchmarked against the well-known LEACH and CELRP protocols. The outcomes show a significant improvement in the WSN in terms of energy efficiency and the overall performance of WSN.
\end{abstract}

\section{Introduction}

Wireless sensor technology is playing a vital role in many of the commercialized industrial automation processes and various other real life applications [1-4]. It is particularly suitable for harsh environment applications where deploying of other network infrastructure is difficult and/or almost impossible such as in battlefield, in hazardous chemical plant, and in high thermal environment. It is not uncommon to see that most of the crucial surveillance and security applications also rely on sensor based applications. Sensors which are tiny in size and cheap in cost have the capabilities to be deployed in a range of applications as explained in [5-9]. Essentially all sensor networks comprise some forms of sensing mechanism to collect data from an intended physical environment either by a time driven approach or by event triggering approach. By these approaches a sensor will convey the sensed data to a destination or sink (multiple destinations/sinks are also possible) via some kinds of routing algorithm such as Minimum Cost Forwarding Algorithm (MCFA), Directed Diffusion Routing Protocol (DDRP), or one of the clusterbased routing protocols. Being very small in size, sensor nodes are built with limited computational capacity, small storage memory, and finite battery power capacity [10].

The structure of a typical WSN node [11] consists of four main components: a sensing element, normally used for sensing a physically measureable parameter; an Analogto-Digital Converter (ADC), used for converting analog signals to some digital formats; a processing unit, providing simple/basic data processing and computation capabilities; and a power unit, responsible for sensor node's operation life span. It is a known fact that WSN is a resource constrained network in which energy efficiency is always the main issue since the operation of WSN depends heavily on the life span of the sensor nodes' battery [12]. The most energy consuming operation in WSN is the data packet routing activity. The characteristics of the WSN are different from the conventional networks $[13,14]$. These unique characteristics are often taken into account for addressing the issues and challenges related to network coverage, runtime topologies management, node distribution, node administration, node mobility energy efficiency/consumption, network deployment, application areas/environment, and so forth [15-17]. 
Nodes in a WSN are generally energy, computation, and memory constrained. Consequently, there is a need for research and development into low-computation resourceaware algorithms for WSNs, targeting at small, highly resource constrained embedded sensor nodes. Energy consumption is of prime importance in WSNs and thus some algorithms [18-24] and hardware were designed with energy efficiency or energy awareness as a central focal point of interest. Enhancing energy efficiency of WSN with respect to the communication routing protocol is the primary concern of this research. We propose a new routing protocol entitled "Position Responsive Routing Protocol (PRRP)" and compare its performance with the well-known LEACH and CELRP protocols. The simulation results show a significant improvement over the aforementioned protocols in terms of energy efficiency and the overall performance of the WSN.

\section{Literature Review}

The main operational sustainability concern in WSN is its energy resource constraint. This brings along in recent years that a great number of energy efficient routing protocols have been proposed for WSNs based on the network organization and the routing protocol operations. Some of these focused on minimizing the communication distance to reduce the energy consumption and a handful of them focused on fair energy distribution to avoid the routing hole (hot spot) problems $[25,26]$. The routing hole issue was described and addressed in [25-28] by utilizing mobility based energy efficient routing protocols. These protocols are suitable in certain situations; however they may not be applicable in cases where mobility is not feasible such as earthquake, forest fire, and disaster management [29]. Mobility techniques do have other challenges like increased energy overhead owing to frequent network topology changes and data packet drops due to high latency $[30,31]$. Various other research papers focusing on energy efficiency routing protocols can be found in [32-37]. Many researchers pay attention to the WSN energy issue by designing different routing techniques and MAC-layer protocols to raise the energy level in WSN. Our literature review reveals that a range of different energy efficient routing protocols in the recent past were designed mostly based on the network structure such as hierarchical routing, location routing, and flat based routing. Our extensive literature review also reveals that the existing routing protocols are still facing energy efficiency limitation issues. Critical analyses of some of the popular existing energy efficient routing protocols are presented in this section.

Hierarchal routing protocols are considered more energy efficient when compared with flat and location based routing protocols. A number of hierarchal based energy efficient routing protocols have been referred to in the literature review such as LEACH [38], TEEN and APTEEN [39, 40], PEGASIS [41], MECN and SMECN [35, 42], SOP [43], HPAR [44], VGA [45], Sensor Aggregate [46], TTDD [47], Energy Efficient Self-Healing [48], Energy Efficient Position Based [49], and CELRP [50]. The literature review refers to the fact that the main advantage of hierarchal approach is to control the data duplication and is best suited for data aggregation.
With this format, nodes are not allowed to communicate with the sink directly that they must go through a cluster head for communication purposes, while the cluster head collects the data from different nodes within a specific cluster area, and then it sends the collected data either to another cluster head or directly to the sink. This approach is more balanced and energy efficient comparable to flat and location based routing protocols [51-57]. However, the disadvantage of this approach is that it results in quick energy drain of the cluster head nodes as most of the time they are involved in sending and receiving the data packets. Rotation of cluster heads is possible but it also brings along an issue related to the loss of the energy resource.

A number of different protocols have been proposed for WSN node localization or location based routing. These include GAF [58], GEAR [59], SPAN [60], MFR, GEDIR [61], and GOAFR [62]. These literatures referred to the fact that the main advantage of these protocols is the ability to identify the correct location of the sensor node within the sensor network. Node localization is directly linked to energy efficiency of WSN. It saves energy resources of WSN. However in most cases these protocols resulted in energy loss due to its geographical topology and node distribution in the WSN. There is thus still a gap in energy efficient routing protocol design and solutions for this class of routing.

A good number of flat based routing protocols have been studied such as SPIN [63], Directed Diffusion [64-66], Rumor Routing [67], GBR [68, 69], MCFA [70], COUGAR [71], CADR [72], ACQUIRE [73], and EAR [74]. The literature review referred to the fact that the main advantage of flat based routing protocol is its simplicity in operation and it had a direct communication mechanism with the base station in which all nodes are allowed to participate during the routing operation. For its simplicity, the nodes only need information about their closest neighbors. However, the major disadvantage is that nodes spread out in a flat manner and all nodes are attempting to participate equally thus causing the nodes closer to the sink to deplete their power sooner than those located further away from the sink. This is mainly due to the heavy data transmission load. This is badly affecting the nodes closer to the sink for keeping them alive longer. Therefore the nodes further away may be unable to communicate with the base station after some time due to network isolated segmentation problem in the WSN. Consequently many of the nodes are not able to participate in routing thus not utilizing their entire energy effectively. More research works are deemed necessary to address the WSN energy efficiency in this aspect. In addition, flat routing is still having issues in data collision overhead, links formed on the fly without synchronization, energy dissipation depending on traffic patterns, and fairness being not guaranteed.

\section{PRRP Research Methodology}

This research is aimed to design a new energy efficient routing protocol, namely, Position Responsive Routing Protocol (PRRP), to address the energy issues in WSN and specifically to enhance the energy efficiency in WSN. The main contribution of PRRP is the novel way of selecting the 
cluster head $(\mathrm{CH})$ in WSN. In comparing to the existing protocols such as LEACH and CELRP whereby the CHs are chosen randomly among all nodes based on their respective residual energy, in PRRP we considered different parameters such as distance from the sink, energy level, and the average distance of neighboring nodes from the candidate $\mathrm{CH}$ node.

3.1. Basic Assumptions. PRRP differs from existing protocols such as LEACH and CELRP in many ways. This research assumes that nodes are aware of their geographical locations in WSNs using GPS or some other cost effective location surveys [50, 75-79]. Each node is able to use different frequencies for transmitting and receiving as it is assumed that sensor node has a multichannel transceiver. It is assumed that each node can transmit its data to the sink as node has ability to transmit for longer distance. All nodes have homogeneous energy level at initial stage and this assumption is widely used in literature [80]. Sensor nodes are distributed in the grid format with a uniform random fashion and the sink is placed in the center of sensor network. This assumption is particularly relevant for forest fire surveillance systems and disaster management systems.

3.2. Network Model. The conceptual network model for PRRP implementation has the layout as shown in Figure 1. It is considered a randomly uniform distributed WSN where nodes are distributed randomly in a sensor field based on a grid format. The static sink is located in the center of the network. The sensor nodes in the network are divided into different groups of clusters on both side of the sink. Normally, the tiers are defined in radii around the sink ranging within tier $D_{0}$, tier $D_{1}$, and so forth, depending on the network size. Each tier covers more than one grid (partially or fully) and has a logical range in which the number of nodes lies, which is depending on the distribution of the nodes. Initially, a signal with energy level $E_{0}$ is transmitted from the sink into the network. The signal with energy $E_{0}$ shall be received only by those nodes placed near the sink. After listening to the signal, these nodes will respond to the sink and they will be registered as tier $D_{0}$ nodes. Next, the sink will advertise signal with transmission energy of $E_{1}$, where $E_{1}>E_{0}$. The nodes, other than $D_{0}$, shall respond to this signal, forming tier $D_{1}$ nodes. This process will be repeated until a preset number of tiers are formed.

3.3. Energy Model. The power control model used in this research work is based on the concept that energy consumption is directly proportional to the transmission distance. Equation (1) below shows the node energy consumption for transmitting $k$ bits of data for a distance of $d$ meters. The energy consumed for receiving of $k$ bits is given by (2) [81]:

$$
\begin{aligned}
& E_{\mathrm{Tx}}=k E_{\text {elec }}+k E_{\mathrm{amp}} d^{2}, \\
& E_{\mathrm{Rx}}=k E_{\text {elec }},
\end{aligned}
$$

where $E_{\text {elec }}$ is the electronics energy in transceiver and $E_{\text {amp }}$ is the amplifier energy.

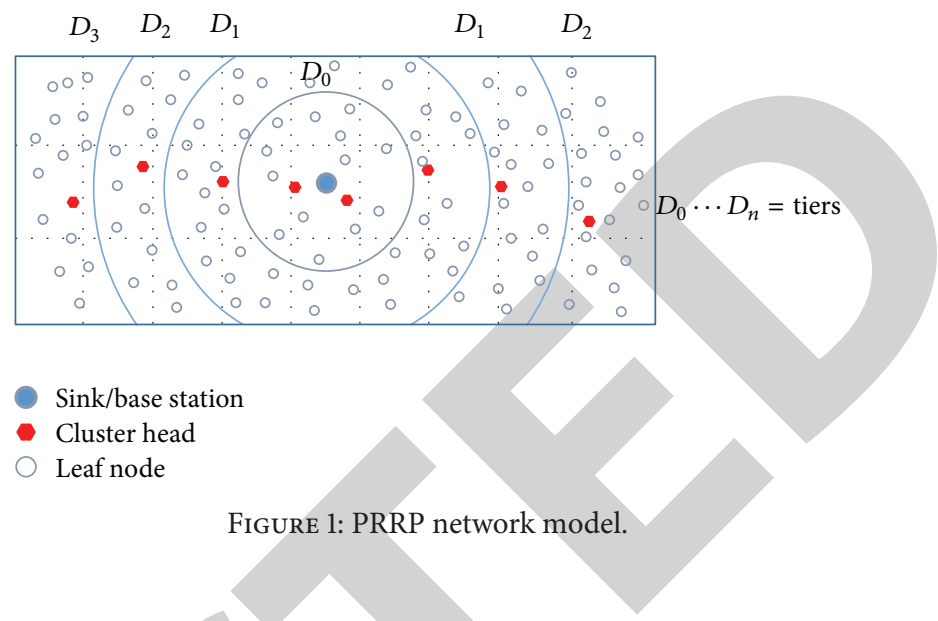

The minimum energy for a node to be able to participate in the coming round of routing (or it is the minimum energy to participate in next round) is given in (3) as $E_{\text {thresholdmin }}$ :

$$
E_{\text {thresholdmin }}=k E_{\text {elec }}+k E_{\text {amp }} d^{2}+8 k E_{\text {elec }} \text {. }
$$

3.4. Analysis of PRRP. This section presents a brief analysis of the energy utilization in terms of energy consumed by cluster head nodes and the leaf nodes that can be linked to the life span of the $\mathrm{CH}$ node. Consider a WSN comprising of $N$ wireless sensor nodes that are uniformly distributed within a grid of size $m \times m$, and within each grid cell one of the nodes acts as the cluster head $(\mathrm{CH})$.

$\mathrm{CH}$ spends its life in three modes, namely, receiving data samples from member nodes, transmitting its own data (and/or member nodes' data), and sleep mode. Let $E_{\text {in }}, E_{\mathrm{th}}, E_{r}$, and $E_{t}$, respectively, denote the initial energy, threshold energy, energy consumed during reception, and energy consumed during transmission of one data sample. Further, we assume that each data sample has a fixed size; therefore the transmitting time and the receiving time for each data sample are the same, namely, $T_{s}$. During each sampling interval, a $\mathrm{CH}$, with $k$ member nodes, spends $T_{t}$ time for transmission, $k T_{t}$ time for receiving samples, and remaining $T_{s}-(k+1) T_{t}$ time in sleep mode. The $\mathrm{CH}$ is assumed to have died when its residual energy falls below the threshold $\left(E_{\mathrm{th}}\right)$ necessary for a node to function. Therefore, the life of the $\mathrm{CH}$ can be calculated in terms of the number of sampling intervals, $N_{s}$, as

$$
N_{s}=\frac{E_{\text {in }}-E_{\text {th }}}{E_{t}+k E_{r}+\left(T_{s}-(k+1) T_{t}\right) P_{s}} .
$$

3.5. Proposed Routing Protocol PRRP Description. After system modeling, suitable gateways are identified from each cluster as all nodes are aware of their respective location and the distance from the sink and from their neighboring nodes. The selection of the gateway is based on parameters such as the node distance, number of nodes close to a particular node, and the energy threshold level. The energy threshold level is more significant than others. On this note, PRRP is therefore aimed to minimize the distance between the nodes and the gateway to save energy during data transmission. 


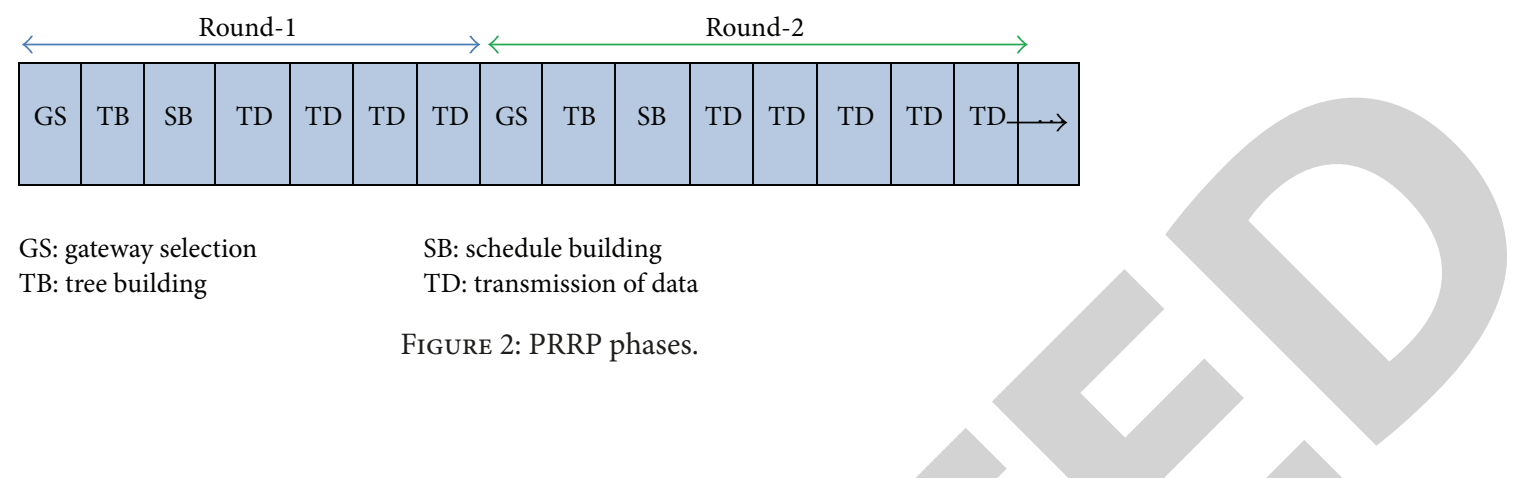

PRRP assumes that node's data acquisition is event driven. That is, the majority of nodes will remain in sleep mode to save energy. It is assumed that type of all the sensed data within one grid is the same, so data aggregation can be applied and nodes will transfer their sensed data on a fixed schedule based on TDMA principle. Each node in PRRP will transmit its data to its closest neighbor. This is to ensure its transmission distance is shortest and therefore less energy is consumed for data transmission. It is noted that tree routing is an energy efficient routing mechanism; thus this mechanism is adopted in the proposed PRRP. A tree is built starting from the leaf nodes to the sink. The sink is placed in the center of the network instead of on the one end as in LEACH and CELRP. It should be mentioned here that, in PRRP, any node on the network can be a gateway but selection of a gateway is based on three parameters as mentioned earlier. Under the PRRP scheme, a node can only be allowed to join a tree if its energy is sufficient to survive for a complete round.

An efficient distributed TDMA scheduling is used in the proposed PRRP. In this scheduling the radio module of the nonleaf node will be turned $\mathrm{ON}$ only for the assigned time slots instead of being ON for all times such as in LEACH protocol. In PRRP the number of leaf nodes and the distance from the nonleaf node is less as compared to LEACH and CELRP. Consequently energy conservation can be optimized based on stated technique. The distributed TDMA scheduling in PRRP strongly supports energy efficiency and good data throughput in the proposed PRRP.

3.5.1. The Proposed PRRP Algorithm. In PRRP, each round of processing time consists of four phases: (1) gateway selection (GS), (2) tree building (TB), (3) schedule building (SB), and (4) transmission of data (TD) as shown in Figure 2. Processing rounds will continue till the routing tree is broken due to the energy level of the gateway dropping below the threshold level.

In the first phase, GS process is completed on the basis of its position, its residual energy level, and the number of neighboring nodes around it. This gateway will be responsible for transferring the aggregated/collected data from the neighboring nodes to the sink. This phase starts with the message initiated from the sink with energy threshold level of $E_{0}$. In the second phase (TB), a routing tree rooted at the sink is built. The newly formed tree will be based on two types of the sensor node such as nonleaf nodes and leaf nodes. Leaf node transmits sensed data from the monitored area to its parent. The nonleaf nodes act as the intermediate nodes to transmit data from lower to upper level of the tree. Based on this tree, a Time Division Multiple Access (TDMA) schedule subsequently is built in phase-3 (SB) in a distributed manner. In the final phase (TD), the data are transmitted from nodes to the sink based on the schedule prepared in phase-3, that is, the distributed TDMA scheduling.

The time required to forward all data packets in a single round is denoted as one data transmission period. That is, a data transmission period may consist of multiple TDs. The TDs may be repeated numerous times in a single round, depending on the energy level of the gateways as illustrated in Figure 2. For instance, in the second round, it has more TDs than in the 1st round. On another note, the number of data transmission periods in a single round shall depend on the application and the periodic events of the sensor network data collection. The PRRP process flow is depicted in Figure 3. Always in case of tree rebuilt, different sensor nodes will take part in that process, which will become source of equal energy distribution in the network. The energy consumption for overall network will be distributed fairly among all nodes. The following sections describe all the phases.

3.5.2. Gateway Selection. In the first phase a few nodes will be selected as gateways in such a manner as to minimize overall energy consumption in the WSN. The network is assumed to be divided into different grid cells and the cells are further divided into a number of tiers, say $n$, on both sides of the sink. Initially the nodes in tier $D_{0}$ will be considered as the potential gateway candidates based on their energy level $e$, the distance from the sink $d$, and the number of neighboring nodes $n$. Some of these nodes are allowed to advertise themselves as gateways. However priority will be based on the residual energy in a node. A potential gateway will act as a gateway until its residual energy drops below a threshold value $E_{\text {th }}$. Following this, new gateways will be selected from the nodes of tier $D_{1}$. Again, the new selected nodes will act as gateways until their residual energy drop below $E_{\text {th }}$, and so on. When all tiers are considered and no more nodes can be selected as gateways based on the current $E_{\text {th }}$, a new round will start with a new lower $E_{\text {th }}$. The flow chart for gateway selection is given in Figure 4.

This mechanism will continue until the last tier $\left(D_{n}\right)$ and with the second cycle the same process will be continued. However, in this time $E_{\text {th }}$ by the sink will be little reduced by factor $(e)$. The same mechanism will be continued for all tiers and all cycles until the end. The sink and sensor nodes will exchange messages using the CSMA mechanism. 


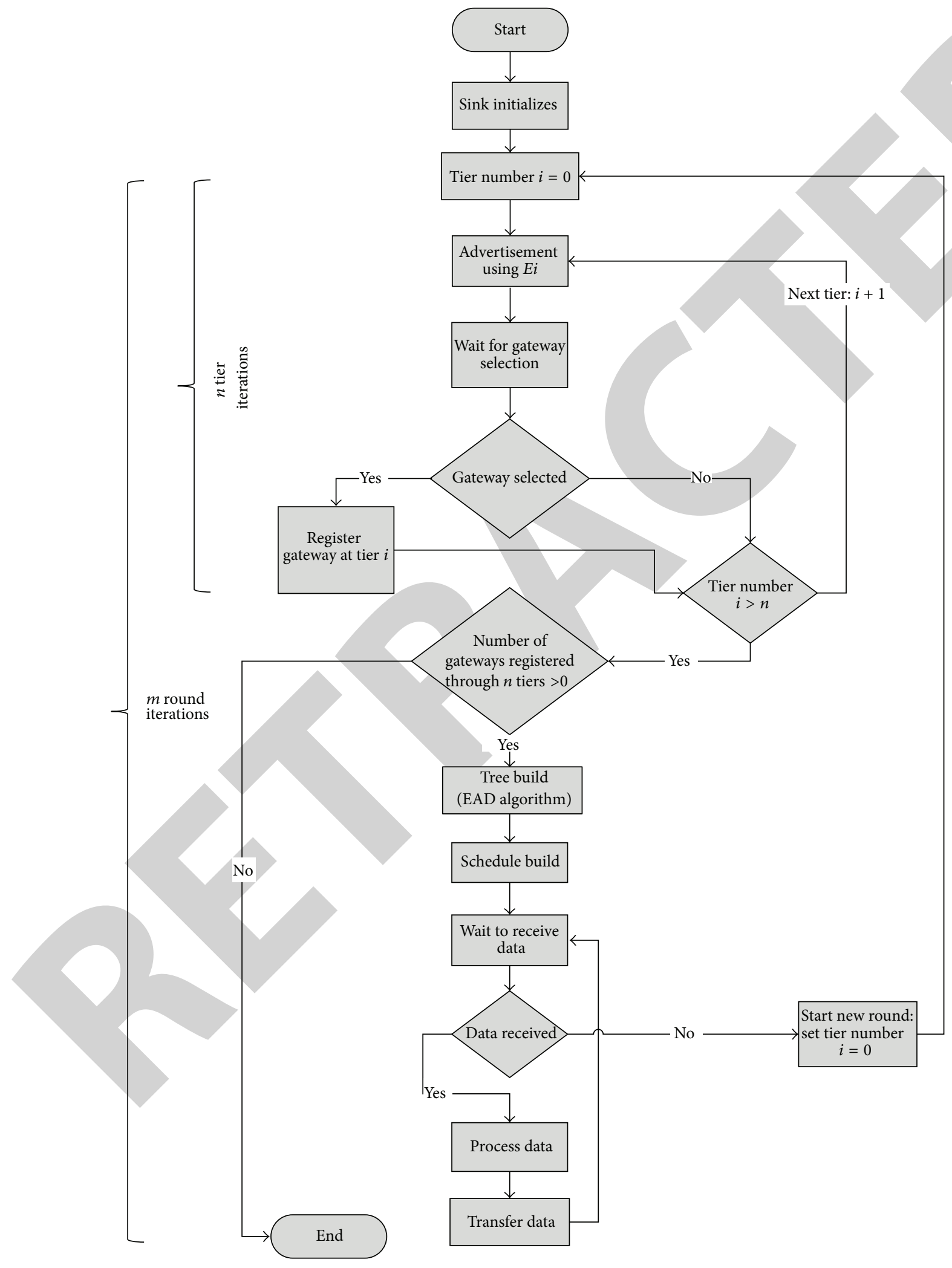

FIGURE 3: PRRP process flow. 


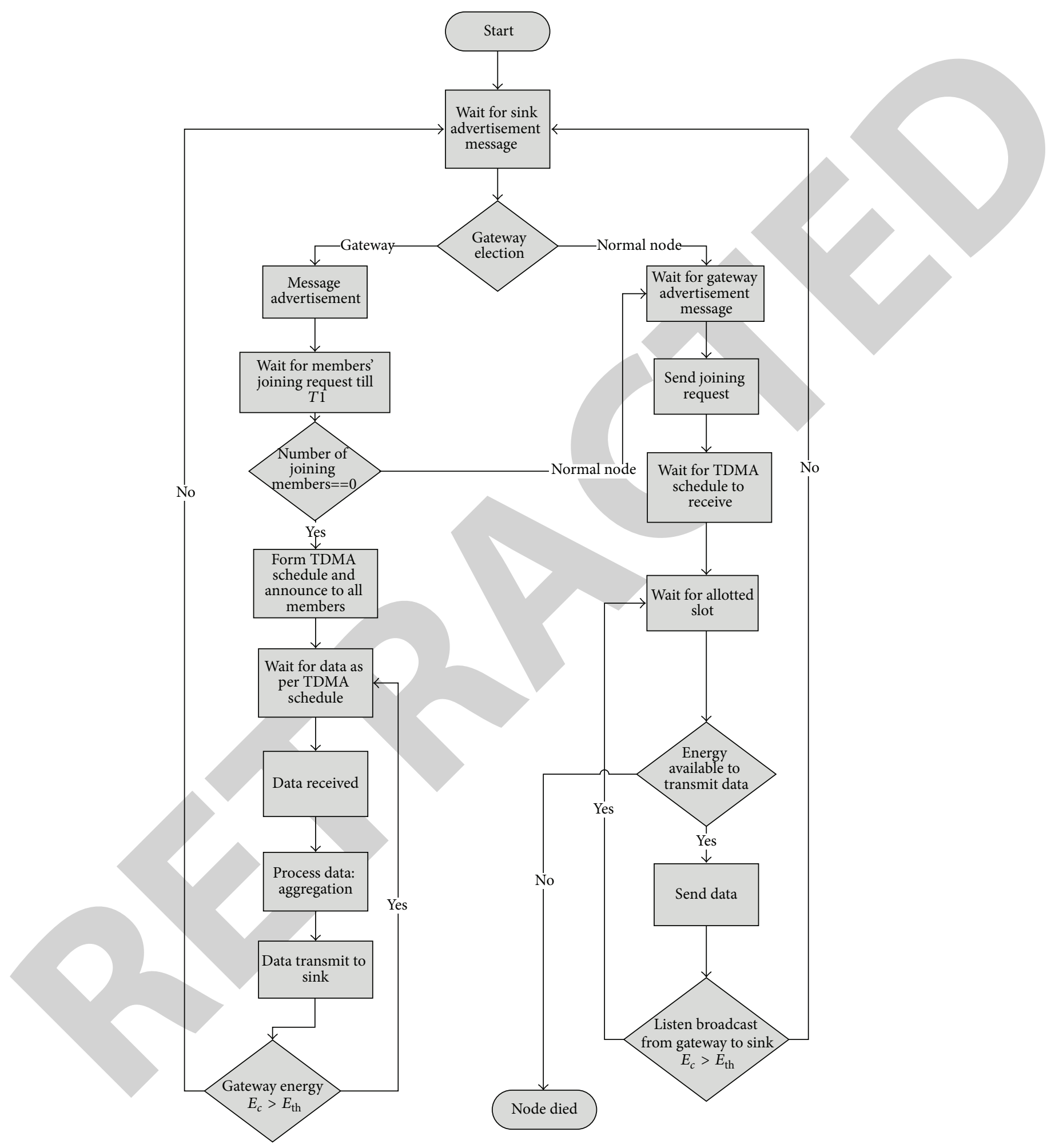

FIGURE 4: Gateway selection flowchart.

The node will remain $\mathrm{ON}$ until it receives the ADV message from the sink and then it sends the JOIN message. Since the node does not need a confirmation from the sink, it will go to sleep immediately after sending the JOIN message. The gateway selection is based on three different parameters such as energy level, number of neighboring nodes, and position from the sink. After selecting the gateways, the next phase will start to build the tree. The gateway nodes will initiate 
Step A:

Wait for sink advertisement message

IF (gateway Election $\rightarrow$ Gateway)

Message advertise

Wait for members' joining request till $\mathrm{T} 1$

IF (number of joining members $==0$ )

Go to Step C

Form TDMA schedule and announce to all members Step B:

Wait for data as per TDMA schedule

Data received

Process data: aggregation

Data transmit to sink

While (Gateway Energy $E_{c}>E_{\text {th }}$ ) Repeat from Step B

Repeat from Step A

ELSE (gateway Election $\rightarrow$ Normal node)

Step C:

Wait for gateway advertisement message

Send joining request

Wait for TDMA schedule to receive Step D:

Wait for allotted slot

IF Energy available to transmit data

Send data

While (Gateway Energy $E_{c}>E_{\text {th }}$ )

Listen Broadcast from sink to gateway

Repeat from Step D

Repeat from Step A

ELSE

Node died

END IF

Algorithm 1: Gateway selection algorithm.

the process of building the tree. For further clarification for the mechanism of gateway selection, the algorithm in pseudocode is given in Algorithm 1.

3.5.3. Tree Building. Upon completing the gateway selection the tree building phase is initiated. A tree rooted at the sink is built by using a modified version of the algorithm proposed in [82]. A tree is built by the sink broadcasting a control message containing six fields, namely, sender, position, type, level, parent, and energy. For a sender node $v, t y p e_{v}$ represents its status in which 0 is for undefined status, 1 is for leaf node, and 2 is for nonleaf node. Level $_{v}$ refers to the number of hops from $v$ to the sink. Parent ${ }_{v}$ is the next hop of $v$ in the path to the sink, energy is the residual energy $E_{v}$, and $P_{v}$ denotes the position of the node from the sink.

Initially each node has status 0 , while sink always have status 2 , implying that sink is a nonleaf node. The sink broadcasts the message $\left(s, 2,0, N U L L, \infty, P_{s}\right)$, where $s$ is the identifier of sink, 2 is the status of the sink, NULL indicates that there is no parent of the sink, $\infty$ indicates that the sink is connected to a power source, and $P_{s}$ is the position of the sink. When a node $v$ receives a message $\left(u, 2\right.$, level $_{u}$, parent $_{u}, E_{u}, P_{u}$ ) from node $u$, it becomes a leaf node, senses the channel until the channel is idle, and then waits for $T_{2}^{v}$ time duration. If the channel is still idle, $v$ will broadcast message $\left(v, 1\right.$, level $\left._{u}+1, u, E_{v}, P_{v}\right)$. If $v$ receives message $(u, 1$, level $_{u}$, parent $\left.{ }_{u}, E_{u}, P_{u}\right)$ from $u$, it will sense the channel until it is idle, and it waits for $T^{v}{ }_{1}$ time duration. If the channel is still idle, $v$ broadcasts message $\left(v, 2\right.$ level $_{v}$, parent $\left.{ }_{v}, E_{v}, P_{v}\right)$. Then, it becomes nonleaf node. If node $v$ receives more than one message from different nodes before broadcasting its message, it will select the node with larger energy and with the nearest distance to it as its parent. If multiple nodes have the same energy and distance, $v$ will select one of them randomly. If there is another node occupying the common channel before its time is out, the waiting node will go back to sensing state. If a node $v$ receives message $\left(w, 2\right.$, $\left._{\text {evel }} w, v, E_{w}, P_{w}\right)$ from node $w$ indicating that $v$ is its parent, $v$ will broadcast message $\left(v, 2\right.$ level $_{v}$, parent $\left.{ }_{v}, E_{v}, P_{v}\right)$ immediately after the channel is idle \{explain why\}. By this process, eventually all gateways will be able to build a routing tree from nodes to the sink as shown in Figure 5.

3.5.4. Schedule Building. The schedule building is the third phase for building an effective distributed scheduling scheme using TDMA principle for data transmission. The schedule is built on the assumption that all the nodes which are connected with the same gateway will transfer their 


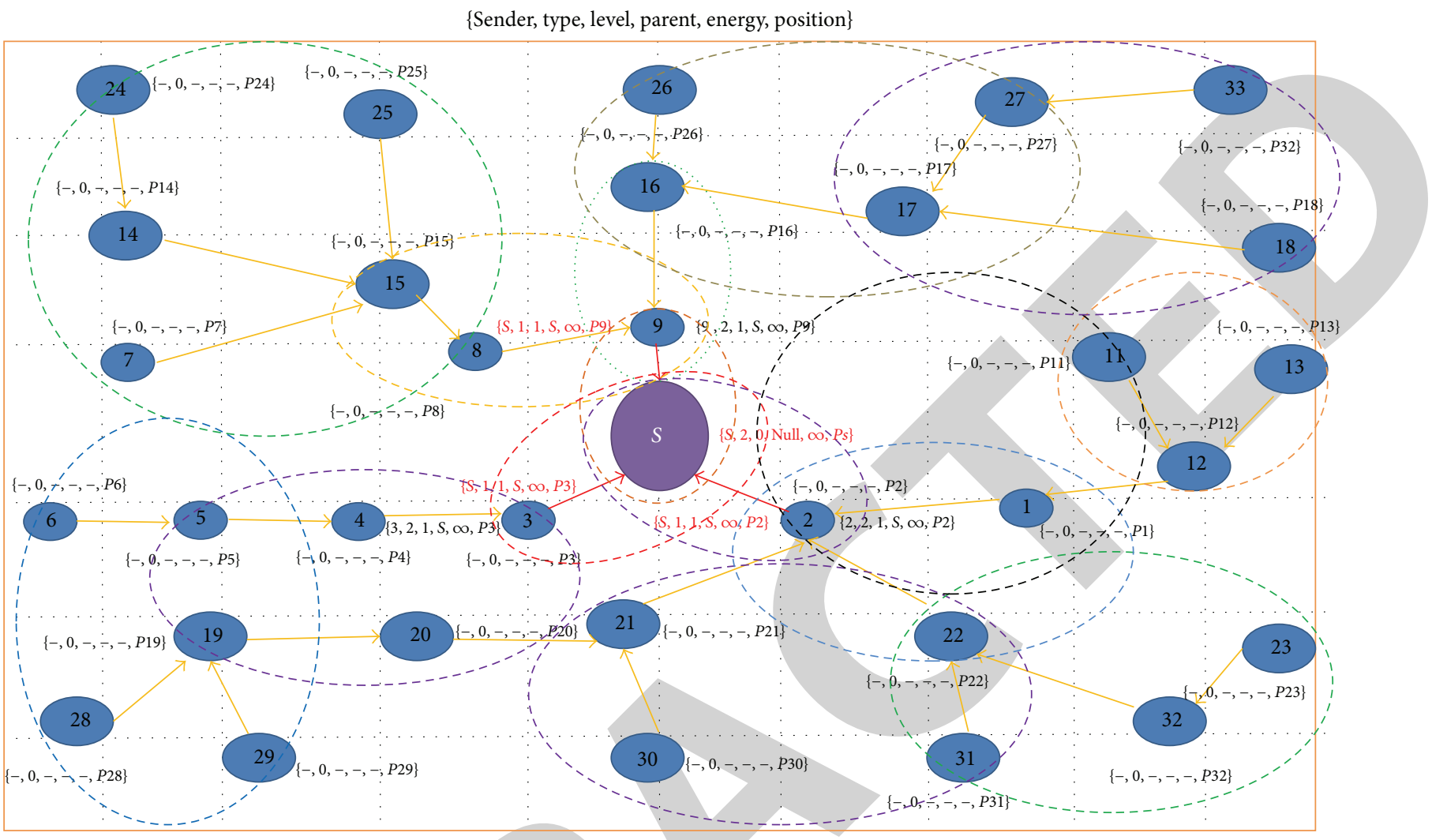

FIGURE 5: Showing final routing trees built among the different regions.

data using same frequency. This assumption implies that nodes connecting to different gateways are using different frequencies for data transmission therefore simultaneous data transmission is allowed among the different trees. We have identified two time constants: Time Ready to Receive (TRR) and Time Ready to Transmit (TRT). TRR $v$ and $\mathrm{TRT}_{v}$ represent two different time slots: $\mathrm{TRR}_{v}$, indicates when a node $v$ is ready to receive from its children nodes and $\mathrm{TRT}_{v}$ shows when a node $v$ can transmit to its parent towards the sink. The node wakeup time, during which its transceiver will stay in the $O N$ state, can be calculated using the values of $\mathrm{TRT}_{v}$ and $\mathrm{TRR}_{v}$. For the leaf node, transmission time $\mathrm{TRT}_{v}$ is equal to the width of one time slot denoted as $t_{0}$, while reception time $\mathrm{TRR}_{v}$ is zero since it does not have any children.

On the other hand, for nonleaf node $v$,

$$
\begin{aligned}
\operatorname{TRR}_{v} & =\max \left(\operatorname{TRT}_{i}\right), \quad \text { where } i=1,2,3, \ldots, n_{v}^{c}, \\
\mathrm{TRT}_{v} & =\operatorname{TRR}_{v}+n_{v}^{c} T_{t} .
\end{aligned}
$$

In the above equation $i$ show an index for the children of $v$ node, $n_{v}^{c}$ represents the count of $v$ 's children which represents one data packet transmit time. As we select max function, the parent node will stay in the $O N$ state only when all of its children are ready to transmit, which is better than switching its state repeatedly from $O F F$ to $O N$ and back. Once the received data from children are aggregated then the parent can transfer the data to the next node. Initially, each leaf node will transmit its TRT value to its parent. After receiving TRT values from all of its children, the parent will calculate its TRT and TRR using above equation and then build a schedule for its children as shown in Figure 6.

The flow chart for building the schedule as explained above is given in Figure 7.

3.5.5. Transmission of Data. The data transmission phase can be repeated many times for a same round of schedule but node will require energy to be alive. Nonleaf node will remain $O N$ for more slots for having responsibility to collect the data from its child and then transfer it to its parent, while the leaf nodes will be $O N$ only for one slot, just to transfer the data to its parent. For each node, a time slot labeled by $T$ represents a time slot at which a node transmits data and a time slot labeled by $R$ represents time slot at which a node receives data as shown in Figure 8.

As a summary, in PRRP the WSN is divided into grid and cells and then into different tiers. Meanwhile, sink is assumed to be placed in the center of the topology. The nodes are distributed in random fashion with an assumption that they are aware of their position/location through Global Positioning System (GPS) or any other local means. The gateways are the nodes that are close to the sink, normally with tier $_{0}$. Furthermore, the gateways are selected with other tiers on the basis of node energy level, its position from the sink, and the number of nodes in its neighbor. PRRP operates in different phases starting from the gateway selection up to 




FIGURE 6: Building TRT and TRR scheduling time.

the data transfer. A tree rooted at the sink is formed and then data is collected using a TDMA scheduling technique. PRRP assumes that node can only join its neighbor which is available within the same tier. In such case, the minimum distance is ensured and so energy can be saved during data transfer, whereby each node will select a parent among its closest neighbors to avoid a long distance data transfer. Consequently, the transmission range for nodes is always short. Each node can listen to the transmission of the nodes close to it or available within the same tier. This technique guarantees the distance among communicating nodes is minimum for data transfer hence saving energy.

\section{Performance Evaluations}

4.1. Simulation Parameters. Simulation parameters are shown in Table 1, while few assumptions were made on the basis widely available in literature review such as the fact that there will be no message loss as the physical channel will be reliable. The coverage of the radio is in circular direction and antenna is in omnidirection; nodes are distributed in open area $[81,82]$.

4.2. Comparative Analysis between PRRP and LEACH. In this section, it is attempted to compare PRRP protocol with LEACH. Principally, PRRP is similar to LEACH protocol in which any node can communicate with the sink and the data collection or transmission mechanism is the time based schedule. The differences between them lie on several factors.
Firstly, in LEACH the clusters and cluster heads are formed within each cluster for the data transmission. Those cluster heads normally are responsible for collecting the data from their related clusters and then transfer it to the sink. On the other hand, a tree in PRRP is constructed rooted to the sink and the gateways are responsible for transferring the data to the sink. Finally, the number of children is less in PRRP compared with LEACH. On comparing the performance evaluation among LEACH and PRRP on different aspects such as energy efficiency, number of live nodes, network throughput/goodput, and average consumed energy per packet for different data transmission periods, it is observed that, in LEACH, there are two types of sensor nodes such as nonhead node and cluster head while in PRRP there are three types of the sensor nodes such as gateway nodes, leaf nodes, and nonleaf nodes. Energy can be consumed in both protocols during transmitting, receiving, and idle listening state.

While comparing both protocols after several periods of data transmission, PRRP showed significant improvement as illustrated in Figure 9, collectively for all rounds together including 1, 5, and 10 rounds altogether. Simulation results illustrate that with PRRP nodes can stay longer and utilize their maximum possible energy for longer time period. For example, after a 10-round test run, the figure shows that the last node of the LEACH protocol dies after 275 seconds while PRRP nodes start dying after 350 seconds.

4.2.1. Comparative Analysis: Total Energy Consumed. In PRRP, during tree formation phase nodes can transmit signals 
TABLE 1: Simulation parameters.

\begin{tabular}{|c|c|}
\hline Parameter & Value \\
\hline Network area & $200 \mathrm{~m} \times 200 \mathrm{~m}$ or $400 \mathrm{~m} \times 400 \mathrm{~m}$ \\
\hline Number of sensors & 200 or 400 \\
\hline Location of the sink & Center of the area \\
\hline Radio range & $50 \mathrm{~m}$ \\
\hline Routine data source probability & \\
\hline Failure rate & \\
\hline Time-out constant & \\
\hline Delay for retransmission $M$ & $0.02 \mathrm{~s}$ \\
\hline Initial energy in each node & $2 \mathrm{~J}$ \\
\hline Control packet size & 48 bytes \\
\hline Data packet size & 100 bytes \\
\hline$E_{\text {threshold }}($ single data transmission period) & $4 \times 10^{-4} \mathrm{~J}$ \\
\hline$E_{\text {th }}($ initial $)$ & $1 \mathrm{~J}$ \\
\hline$e$ & 0.5 \\
\hline
\end{tabular}

with minimum energy level as closer node can be selected by the parent which saves the node energy by reducing distance. In PRRP, parent can be any node and can select the closer nodes to save its energy level. However, LEACH does not consider the location or the distance among nodes with an assumption that each node can hear all other nodes in the network. The transmission distance is shorter in PRRP. In LEACH, the main reasons for energy consumption are, for example, longer distance among the nodes and cluster head and that nodes randomly advertise themselves as cluster heads based on the energy level of the nodes. In LEACH, with most of the cases nominated cluster heads are at longer distance from the normal nodes which becomes one more reason for energy loss compared to PRRP. Furthermore, by comparing nonleaf node and the cluster head node of LEACH, it can be seen that nonleaf nodes in PRRP consume little energy due to the idle listening state while they wait to receive and transmit data at the specific time slots only, while LEACH has different approach completely. In addition each cluster head has more number of children compared to PRRP and cluster head requires more time to be in $\mathrm{ON}$ state which becomes one more reason for comparatively more energy loss than PRRP.

Figure 10 shows an illustration for different rounds among LEACH and PRRP; if compared with 10 data transmission periods at $(t=150)$ seconds, total consumed energy is around $220 \mathrm{~J}$ in LEACH and $120 \mathrm{~J}$ in PRRP. The consumed energy is dropped which is quite significant, though PRRP shows significant improvement for overall energy consumed compared till the end of the network lifetime and higher throughput for the same initial energy level.
4.2.2. Comparative Analysis on per Packet Average Consumed Energy. When comparing PRRP with LEACH on the basis of average energy consumed per packet, it is found that PRRP consumes less energy as shown in Figure 11. The observations show that, in PRRP with the initial data transmission periods, the average consumed energy is higher. On the other hand, when comparing PRRP and LEACH with more rounds of data transfer, it is found that PRRP is more efficient than $\mathrm{LEACH}$. The reason for more average energy consumed in the initial round in PRRP protocol with single data transmission phase is that the initial setup cost is little higher and energy consumed in initial phases is considered to be overhead energy. However, PRRP outperforms LEACH for average per packet energy use after completing its entire round.

4.2.3. Comparative Analysis on the Basis of Throughput. Table 2 describes the network throughput comparison between LEACH and PRRP in terms of the data packets delivery to the sink. Simulation results show significant improvement of network throughput for all rounds including 01, 05, and 10. PRRP saves a great amount of energy during data transmission phase for multiple periods. Overall significant performance improvement is seen based on several factors such as enhancement in the network life time, energy efficiency, and utilizing maximum possible energy of each individual sensor network node; with the increase in rounds, the network throughput even increases more.

4.3. Comparative Analysis between PRRP and CELRP. This section is aimed at comparing PRRP and CELRP based on 
TABLE 2: A comparison between PRRP and LEACH in terms of throughput.

\begin{tabular}{|c|c|c|c|}
\hline Periods & PRRP & LEACH & Improvement with PRRP in \% \\
\hline 1 data transmission period & 15834 & 3607 & 4.38 times \\
\hline 5 data transmission periods & 53950 & 13045 & 4.13 times \\
\hline 10 data transmission periods & 64100 & 25640 & 2.50 times \\
\hline
\end{tabular}

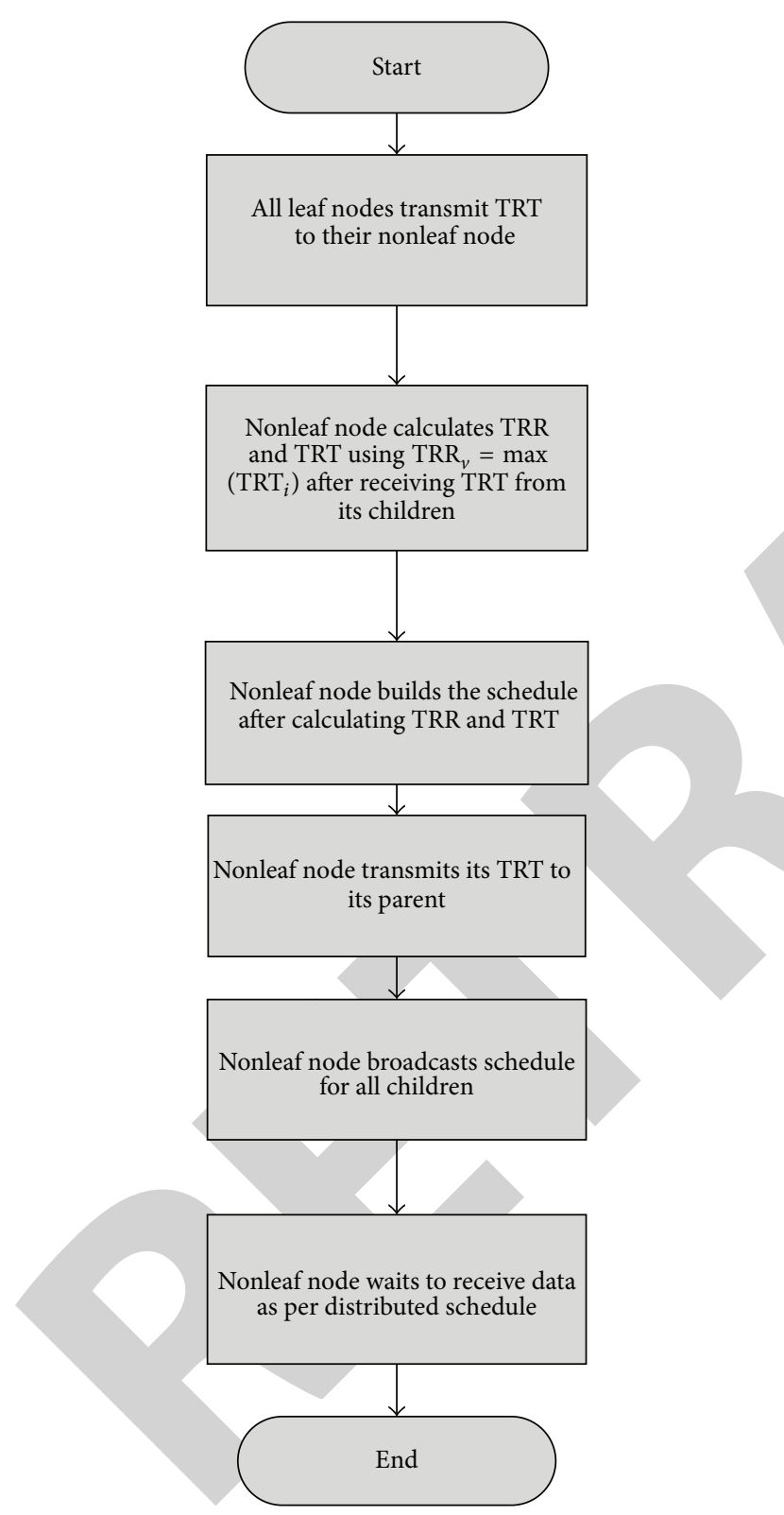

FIGURE 7: Flow chart for building time schedule.

their operation and node types, as described earlier that in PRRP there are three types of the nodes including nonleaf node, leaf node, and gateway nodes, while in CELRP the situation is different where nodes are either cluster head or nonhead nodes while cluster head leader (CHL) can be chosen from available cluster heads. The sink in CELRP is placed outside of the network which increased the distance from among the cluster heads, cluster head leaders, and the sink, while the situation is different with PRRP where the sink is placed in the center of the network and all nodes are fairly distributed around it which becomes one of the main reasons for lower distance among the nodes and the sink. Figure 12 shows a great difference among PRRP and CELRP for different periods such as 01,05 , and 10 . PRRP outperforms CELRP with the increase of periods as it can be observed. PRRP allows any node to become gateway provided on its energy level, if it distributes fairly energy consumption for the entire network, while the situation is the different in CELRP.

4.3.1. Comparative Analysis: Total Energy Consumed. Tree building, effective TDMA scheduling, and data transmission phases are the strength of PRRP; each phase has an edge over CELRP. In PRRP, during tree building nodes normally transmit signals with minimum energy level as closer nodes can be selected by the parents. This technique is ensuring to reduce the distance among the parent and child node as energy can be saved during data transmission. In addition with PRRP the sink is also placed in the center of the network to reduce the overall distance for each sensor node including leaf node, nonleaf node, and gateways. PRRP also has consideration for location of neighboring nodes in order to reduce the data transmitting distance. The situation is different with CELRP where nodes can act as normal nodes, cluster heads, and cluster head leaders while sink is placed outside the distance. Hence longer data transmission distances become one of the major reasons for more energy loss compared with PRRP. Figure 13 shows significant difference among results for total consumed energy for different rounds such as 01,05 , and 10 , respectively. In PRRP an effective TDMA schedule is also implemented for transmitting data on their respective times and in addition to keep nodes $O N$ only for required time slots which has great effects on overall energy efficiency of sensor network and can be observed through Figure 13.

As an illustration, we can compare results of PRRP and CELRP at any stage in Figure 13; consider for 10 data transmission periods at $(t=150)$ seconds consumed energy is $230 \mathrm{~J}$ in CELRP and $140 \mathrm{~J}$ in PRRP. The consumed energy is dropped which is quite significant. Overall performance of PRRP over CELRP is significant as can be noticed from Figure 13.

4.3.2. Comparative Analysis: Per Packet Average Consumed Energy. In this analysis, PRRP and CELRP protocol are compared on the basis of the average consumed energy per packet as shown in Figure 14. It is found from our observations that CELRP initially shows good performance for average energy per packet compared to PRRP. However, after a short span 


\begin{tabular}{|c|c|c|c|c|c|c|c|}
\hline Node 14 & $T$ & & & & & & \\
\hline \begin{tabular}{|l|} 
Node 13 \\
\end{tabular} & & $T$ & & & & & \\
\hline Node 12 & $T$ & & & & & & \\
\hline Node 11 & & $T$ & & & & & \\
\hline Node 10 & $R$ & $R$ & & & $T$ & & \\
\hline Node 9 & $R$ & $R$ & & & & $T$ & \\
\hline Node 1 & & & & $R$ & $R$ & $R$ & $T$ \\
\hline Sink & & & $R$ & $R$ & & & $R$ \\
\hline Node 3 & $R$ & $R$ & $T$ & & & & \\
\hline Node 2 & $R$ & $R$ & $R$ & $T$ & & & \\
\hline Node 4 & & $T$ & & & & & \\
\hline Node 7 & & $T$ & & & & & \\
\hline Node 5 & $T$ & & & & & & \\
\hline Node 6 & & & $T$ & & & & \\
\hline Node 8 & $T$ & & & & & & \\
\hline Time slot & $\infty$ & $\begin{array}{l}\mathrm{H} \\
+ \\
0\end{array}$ & $\begin{array}{l}+ \\
+ \\
+ \\
+\end{array}$ & $\begin{array}{l}+ \\
+ \\
+ \\
+\end{array}$ & $\begin{array}{l}+ \\
+ \\
+ \\
+\end{array}$ & $\begin{array}{l}\text { in } \\
+ \\
+\end{array}$ & $\begin{array}{l}5 \\
+ \\
+\end{array}$ \\
\hline
\end{tabular}

FIGURE 8: Data transmission scheduling.

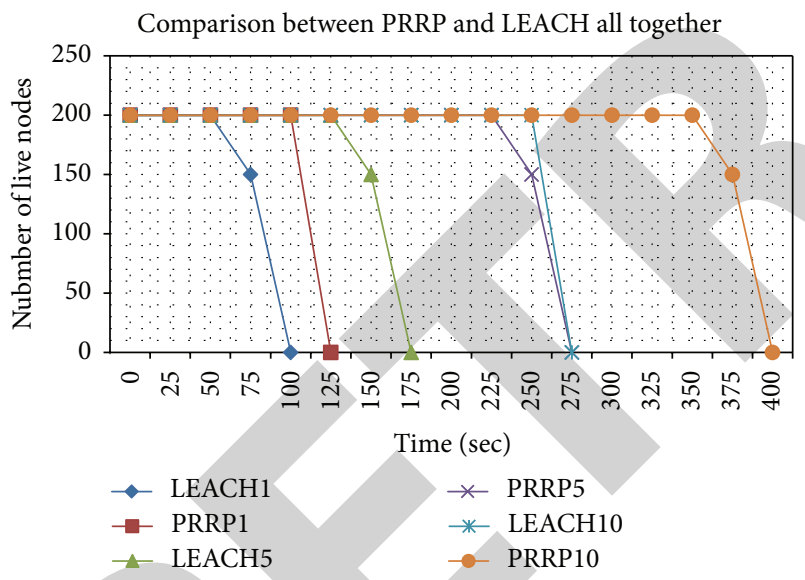

FIGURE 9: Number of live nodes versus time (collectively for 1, 5, and 10 rounds).

of time PRRP shows a significant improvement in it with the increased number of data periods.

On the other hand, when comparing PRRP and CELRP with more rounds of data transfer, it is found that PRRP is more efficient than CELRP. In PRRP, the reason for more average energy consumed at the initial round is that the three initial phases are for setup and there is no data transmission during this. So, the energy consumed in these initial phases is considered to be overhead energy, which is more than the energy saved in data transmission phase for first period. PRRP stands for high performance for average per packet energy use after completing its entire round and especially after continuing its several transmission periods with its initial build tree.

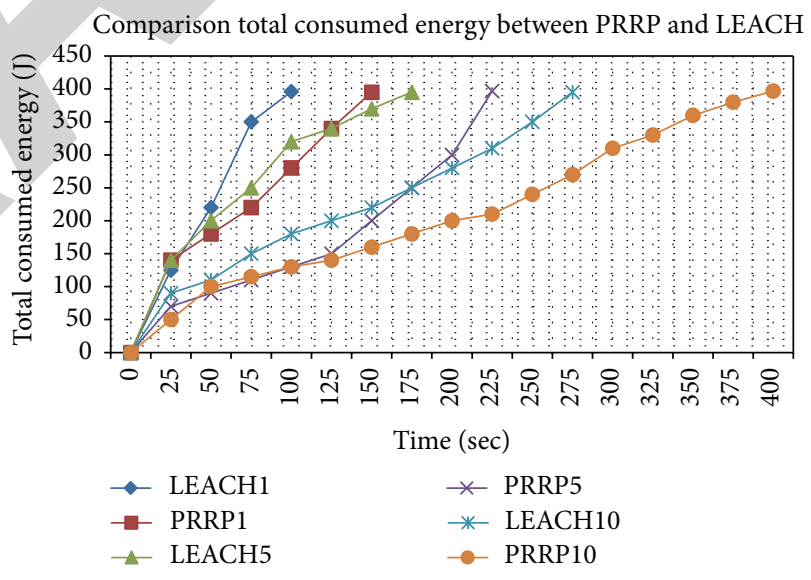

FIGURE 10: Total consumed energy versus time (LEACH and PRRP).

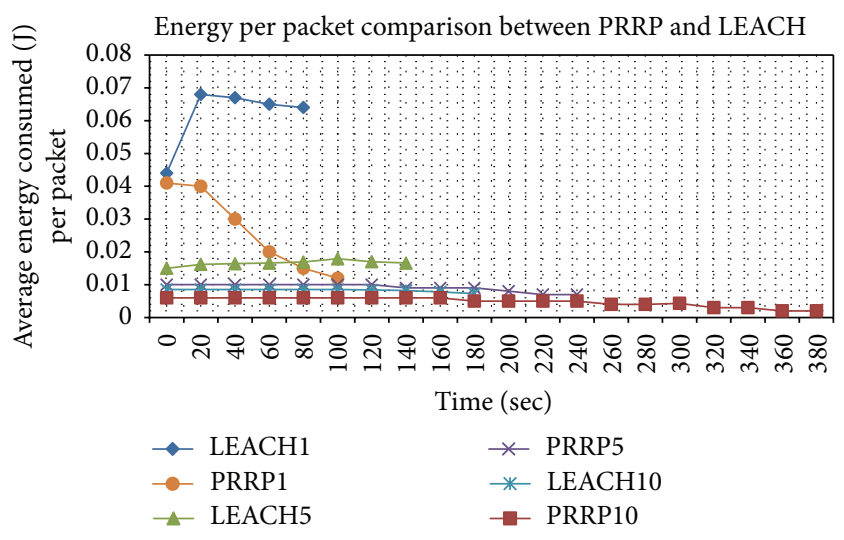

FIgURE 11: Average consumed energy per packet (PRRP and LEACH). 
TABLE 3: A comparison between PRRP and CELRP in terms of throughput.

\begin{tabular}{lccc}
\hline Periods & PRRP & CELRP & Improvement with PRRP\% \\
\hline 1 data transmission period & 16733 & 5950 & 2.81 times \\
5 data transmission periods & 54555 & 19985 & 2.72 times \\
10 data transmission periods & 65305 & 35710 & 1.82 times \\
\hline
\end{tabular}

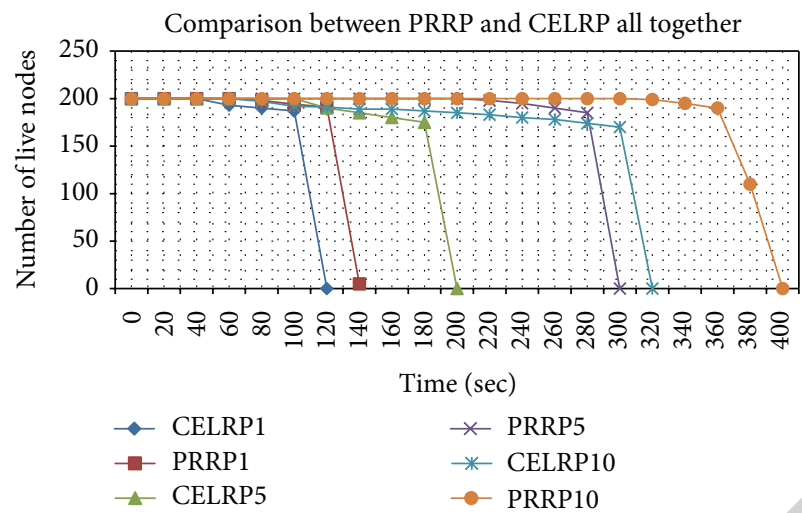

FIGURE 12: Number of live nodes versus time (PRRP and LEACH collectively).

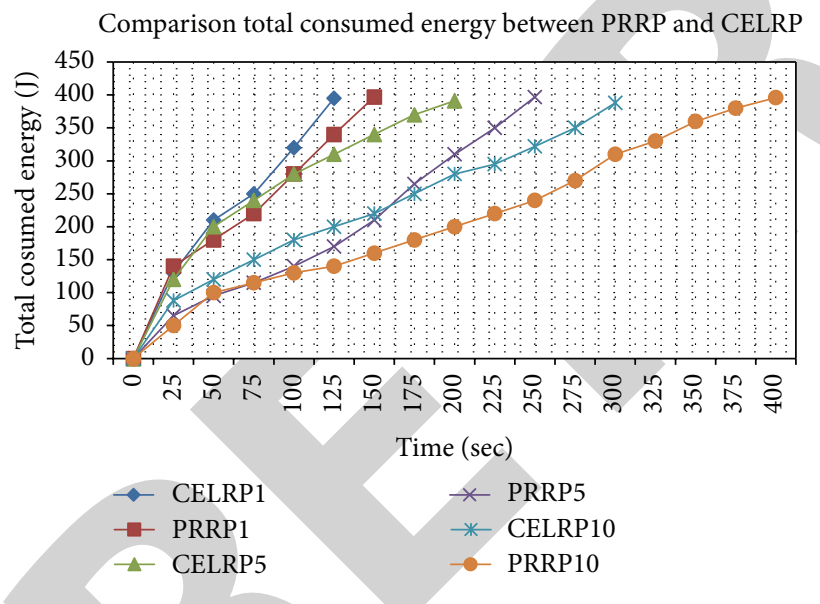

FIGURE 13: Total consumed energy versus time (CELRP and PRRP).

4.3.3. Comparative Analysis on the Basis of Throughput. Following Table 3 describes the network throughput comparison between PRRP and CELRP in term of the data packets delivery to the sink. Simulation results show significant improvement of network throughput for all rounds including 01, 05, and 10. PRRP saves a great amount of energy during data transmission phase for multiple periods. Overall significant performance improvement is seen based on several factors such as enhancement in the network life time, energy efficiency, and utilizing maximum possible energy of each individual sensor network node; with the increase in rounds, the network throughput even increases more.

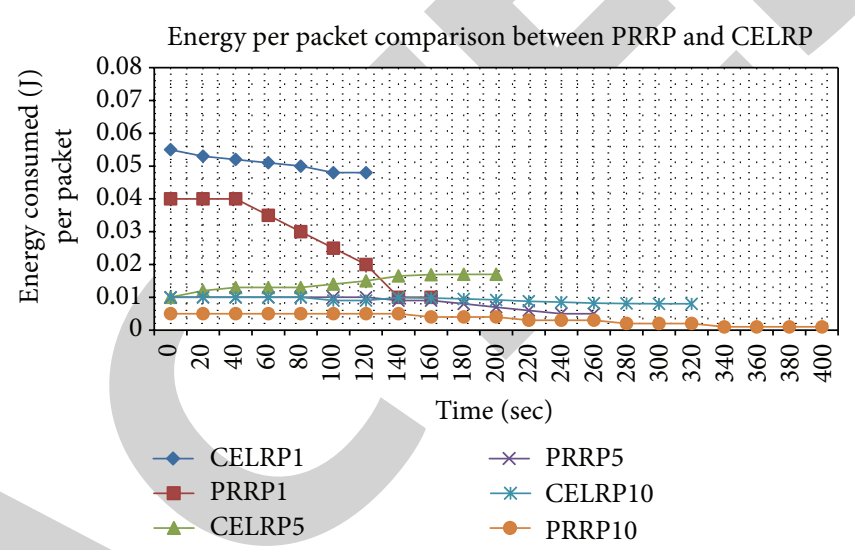

FIGURE 14: Average consumed energy per packet (PRRP and CLERP).

\section{Conclusion}

The performance of PRRP is evaluated on the basis of energy lifetime, average energy consumption of the network both individually and per packet basis, and the network throughput. The theme is to discuss the results of PRRP and its performance as compared to the existing routing protocols such as LEACH and CELRP. PRRP shows better results when compared with LEACH, where PRRP shows an impressive performance in the form of improving the network lifetime (by reducing the energy consumption) and the network throughput. The throughput is increased by 2.5 times and network lifetime is improved by more than $50 \%$ while the energy consumption per packet is reduced to less than 50\%. The comparative analysis of PRRP against CELRP shows that PRRP increased the throughput of the network by 1.82 times, network lifetime is improved more than $35 \%$, and the energy consumption is reduced by more than $35 \%$.

\section{Competing Interests}

The authors declare that there is no conflict of interests regarding the publication of this paper.

\section{References}

[1] E. A. Basha, S. Ravela, and D. Rus, "Model-based monitoring for early warning flood detection," in Proceedings of the 6th ACM Conference on Embedded Networked Sensor Systems (SenSys '08), pp. 295-308, New York, NY, USA, November 2008.

[2] A. Ellaboudy, K. Pister, and EECS Department UC Berkeley, "Outlet power monitoring using wireless sensor networks," 
Tech. Rep. UCB/EECS-2012-152, Electrical Engineering \& Computer Sciences Department, Fremont, Calif, USA, 2012, http://www.eecs.berkeley.edu/Pubs/TechRpts/2012/EECS-2012152.html.

[3] G. Zhao, "Wireless sensor networks for industrial process monitoring and control: a survey," Network Protocols and Algorithms, vol. 3, no. 1, pp. 47-63, 2011.

[4] M. Paavola, "Wireless technologies in process automation-a review and an application example," Report A 33, Control Engineering Laboratory, University of Oulu, Oulu, Finland, 2007.

[5] K. Maraiya, K. Kant, and N. Gupta, "Application based Study on Wireless Sensor Network," International Journal of Computer Applications, vol. 21, no. 8, pp. 9-15, 2011.

[6] M. Erol-Kantarci and H. T. Mouftah, "Wireless multimedia sensor and actor networks for the next generation power grid," Ad Hoc Networks, vol. 9, no. 4, pp. 542-551, 2011.

[7] B. Lu and V. C. Gungor, "Online and remote motor energy monitoring and fault diagnostics using wireless sensor networks," IEEE Transactions on Industrial Electronics, vol. 56, no. 11, pp. 4651-4659, 2009.

[8] V. C. Gungor and F. C. Lambert, "A survey on communication networks for electric system automation," Computer Networks, vol. 50, no. 7, pp. 877-897, 2006.

[9] J. Buckley, K. Aherne, B. O’Flynn, J. Barton, A. Murphy, and C. O'Mathuna, "Antenna performance measurements using wireless sensor networks," in Proceedings of the IEEE 56th Electronic Components and Technology Conference, pp. 16521657, San Diego, Calif, USA, May 2006.

[10] S.-H. Yang, "Principlas of wireless sensor networks," in Wireless Sensor Networks Principles, Design and Applications, Signals and Communication Technology, pp. 7-47, Springer, London, UK, 2014.

[11] J. N. Al-Karaki and A. E. Kamal, "Routing techniques in wireless sensor networks: a survey," IEEE Wireless Communications, vol. 11, no. 6, pp. 6-27, 2004.

[12] K. Kaur and B. Singh, "Wireless sensor network based: design principles \& measuring performance of IDS," International Journal of Computer Applications, vol. 1, no. 28, pp. 94-99, 2010.

[13] I. F. Akyildiz, W. Su, Y. Sankarasubramaniam, and E. Cayirci, "A survey on sensor networks," IEEE Communications Magazine, vol. 40, no. 8, pp. 102-105, 2002.

[14] M. Chu, H. Haussecker, and F. Zhao, "Scalable informationdriven sensor querying and routing for ad hoc heterogeneous sensor networks," International Journal of High Performance Computing Applications, vol. 16, no. 3, pp. 293-313, 2002.

[15] S. K. Singh, M. Singh, and D. K. Singh, "Routing protocols in wireless sensor networks-a survey," International Journal of Computer Science \& Engineering Survey, vol. 1, no. 2, pp. 63-83, 2010.

[16] G. Kalpana and T. Bhuvaneswari, "A survey on energy efficient routing protocols for wireless sensor networks," International Journal of Computer Applications, vol. 86, no. 12, pp. 12-18, 2011.

[17] Q. Cao, T. Abdelzaher, T. He, and R. Kravets, "Cluster-based forwarding for reliable end-to-end delivery in wireless sensor networks," in Proceedings of the 26th IEEE International Conference on Computer Communications (IEEE INFOCOM '07), pp. 1928-1936, Anchorage, Alaska, USA, May 2007.

[18] R. Singh and G. Mittal, "Lifetime enhancement of cluster head selection for MIMO routing algorithm based on weighted sum method for WSN," International Journal of Engineering Research and Applications, vol. 3, no. 5, pp. 1894-1898, 2013.
[19] S. Manda, N. Archana, and N. Umarani, "Maximizing the lifetime of wireless sensor networks using CRT based packet splitting algorithm," International Journal of Advancements in Research \& Technology, vol. 2, no. 4, pp. 48-58, 2013.

[20] A. E. A. A. Abdulla, H. Nishiyama, and N. Kato, "Extending the lifetime of wireless sensor networks: a hybrid routing algorithm," Computer Communications Journal, vol. 35, no. 9, pp. 1056-1063, 2012.

[21] J. Bahi, M. Haddad, M. Hakem, and H. Kheddouci, "Efficient distributed lifetime optimization algorithm for sensor networks," Ad Hoc Networks, vol. 16, pp. 1-12, 2014.

[22] D. Ebrahimi and C. Assi, "Compressive data gathering using random projection for energy efficient wireless sensor networks," Ad Hoc Networks, vol. 16, no. 1, pp. 105-119, Feb 2014.

[23] J.-Y. Chang and P.-H. Ju, "An energy-saving routing architecture with a uniform clustering algorithm for wireless body sensor networks," Future Generation Computer Systems, vol. 35, pp. 128-140, 2014.

[24] R. S. Bhadoria and D. G. Chandra, "Routing protocol in Wireless Sensor Networks," in Proceedings of the 2nd IEEE Conference on Parallel Distributed and Grid Computing, vol. 35, no. 1, pp. 128-140, February 2012.

[25] N. Gautam, W.-I. Lee, and J.-Y. Pyun, “Track-sector clustering for energy efficient routing in wireless sensor networks," in Proceedings of the IEEE 9th International Conference on Computer and Information Technology (CIT '09), pp. 116-121, IEEE, Xiamen, China, October 2009.

[26] M. T. Nguyen, "Minimizing energy consumption in random walk routing for wireless sensor networks utilizing compressed sensing," in Proceedings of the 8th International Conference on System of Systems Engineering (SoSE '13), pp. 297-301, IEEE, Maui, Hawaii, USA, June 2013.

[27] B. Nazir and H. Hasbullah, "Energy efficient and QoS aware routing protocol for Clustered Wireless Sensor Network," Computers and Electrical Engineering, vol. 39, no. 8, pp. 2425-2441, 2013.

[28] B. Nazir and H. Hasbullah, "Mobile Sink based Routing Protocol (MSRP) for prolonging network lifetime in clustered wireless sensor network," in Proceedings of the International Conference on Computer Applications and Industrial Electronics (ICCAIE '10), pp. 624-629, Kuala Lumpur, Malaysia, December 2010.

[29] W. M. Aioff, G. R. Mateus, and F. P. Quintao, "Optimization issues and algorithms for wireless sensor networks with mobile sink," in Proceedings of the International Network Optimization Conference Spa, pp. 1-6, Spa, Belgium, April 2007.

[30] A. Waheed Khan, A. H. Abdullah, M. H. Anisi, and J. Iqbal Bangash, "A comprehensive study of data collection schemes using mobile sinks in wireless sensor networks," Sensors, vol. 14, no. 2, pp. 2510-2548, 2014.

[31] M. Di Francesco and S. K. Das, "Data collection in wireless sensor networks with mobile elements: a survey," ACM Transactions on Sensor Networks (TOSN), vol. 8, no. 1, article 7, 2011.

[32] M. T. Nguyen and N. Rahnavard, "Cluster-based energy-efficient data collection in wireless sensor networks utilizing compressive sensing," in Proceedings of the IEEE Military Communications Conference (MILCOM '13), pp. 1708-1713, November 2013.

[33] H. Lee and K. Lee, "Energy minimization for flat routing and hierarchical routing for wireless sensor networks," in Proceedings of the 2nd International Conference on Sensor 
Technologies and Applications (SENSORCOMM '08), pp. 735742, Cap Esterel, France, August 2008.

[34] B. He and H. Zhang, "An energy optimization method for wireless sensor network," in Proceedings of the Automatic International Conference on Control and Artificial Intelligence (ACAI '12), pp. 402-406, IEEE, Xiamen, China, March 2012.

[35] V. Rodoplu and T. H. Meng, "Minimum energy mobile wireless networks," IEEE Journal on Selected Areas in Communications, vol. 17, no. 8, pp. 1333-1344, 1999.

[36] W.-Y. Zhang, Z.-Z. Liang, Z.-G. Hou, and M. Tan, "A power efficient routing protocol for wireless sensor network," in Proceedings of the IEEE International Conference on Networking, Sensing and Control (ICNSC '07), pp. 20-25, IEEE, London, UK, April 2007.

[37] T. Liu and F. Li, "Power-efficient clustering routing protocol based on applications in wireless sensor network," in Proceedings of the 5th International Conference on Wireless Communications, Networking and Mobile Computing (WiCOM '09), pp. 1-6, Beijing, China, September 2009.

[38] W. R. Heinzelman, A. Chandrakasan, and H. Balakrishnan, "Energy-efficient communication protocol for wireless microsensor networks," in Proceedings of the 33rd Annual Hawaii International Conference on System Sciences (HICSS '00), vol. 8, p. 8020, Maui, Hawaii, USA, January 2000.

[39] A. Manjeshwar and D. P. Agrawal, "TEEN: a protocol for enhanced efficiency in wireless sensor networks," in Proceedings of the 15th International Parallel and Distributed Processing Symposium, pp. 305-312, IEEE, San Francisco, Calif, USA, April 2000.

[40] A. Manjeshwar and D. P. Agrawal, "APTEEN: a hybrid protocol for efficient routing and comprehensive information retrieval in wireless sensor networks," in Proceedings of the 2nd International Workshop on Parallel and Distributed Computing Issues in Wireless Networks and Mobile Computing, pp. 215-221, Ft. Lauderdale, Fla, USA, April 2002.

[41] S. Lindsey and C. S. Raghavendra, "PEGASIS: power-efficient gathering in sensor information systems," in Proceedings of the Aerospace Conference, pp. 1125-1130, IEEE, March 2002.

[42] L. Li and J. Y. Halpern, "Minimum energy mobile wireless networks revisited," in Proceedings of the IEEE International Conference on Communications (ICC '01), pp. 93-100, Helsinki, Finland, June 2001.

[43] L. Subramanian and R. H. Katz, "An architecture for building self-configurable systems," in Proceedings of the 1st Annual Workshop on Mobile and Ad Hoc Networking and Computing (MobiHOC '00), pp. 63-73, Boston, Mass, USA, August 2000.

[44] Q. Li, J. Aslam, and D. Rus, "Hierarchical power-aware routing in sensor networks," in Proceedings of the DIMACS Workshop on Pervasive Networking, pp. 47-52, May 2001.

[45] J. N. Al-Karaki, R. Ul-Mustafa, and A. E. Kamal, "Data aggregation in wireless sensor networks-exact and approximate algorithms," in Proceedings of the Workshop on High Performance Switching and Routing (HPSR '04), pp. 241-245, Phoenix, Ariz, USA, April 2004.

[46] Q. Fang, F. Zhao, and L. Guibas, "Lightweight sensing and communication protocols for target enumeration and aggregation," in Proceedings of the 4th ACM International Symposium on Mobile Ad Hoc Networking and Computing (MOBIHOC '03), pp. 165-176, Annapolis, Md, USA, June 2003.

[47] F. Ye, H. Luo, J. Cheng, S. Lu, and L. Zhang, "A two-tier data dissemination model for large-scale wireless sensor networks," in Proceedings of the 8th Annual International Conference on Mobile Computing and Networking (MOBICOM '02), pp. 148159, ACM/IEEE Press, Atlanta, Ga, USA, September 2002.

[48] N. Zaman, L. T. Jung, and V. Ponnusamy, "Application of selfhealing in wireless sensor network: a survey," in BiologicallyInspired Energy Harvesting through Wireless Sensor Technologies, pp. 217-218, IGI Global, 2016.

[49] N. Zaman, T. J. Low, and T. Alghamdi, "Enhancing routing energy efficiency of wireless sensor networks," in Proceedings of the 17th IEEE International Conference on Advanced Communications Technology (ICACT '15), vol. 4, no 2, pp. 587-595, GiRI (Global IT Research Institute), Seoul, Republic of Korea, July 2015.

[50] Nurhayati, S. H. Choi, and K. O. Lee, "A cluster based energy efficient location routing protocol in wireless sensor network," International Journal of Computers and Communications, vol. 5, no. 2, pp. 67-74, 2011.

[51] N. Zaman and A. Abdullah, "Energy efficient routing in wireless sensor network: research issues and challenges," in Proceedings of the IEEE International Conference on Intelligence and Information Technology (ICIIT '10), pp. 239-243, 2010.

[52] N. Zaman, L. Tang Jung, F. Alsaade, and T. Alghamdi, "Wireless Sensor Network (WSN): routing security, reliability and energy efficiency," Journal of Applied Sciences, vol. 12, no. 6, pp. 593-597, 2012.

[53] A. Noor Zaman and A. Abdullah, "Different techniques towards enhancing Wireless Sensor Network (WSN) routing energy efficiency and Quality of Service (QoS)," World Applied Science Journal (WASJ), vol. 13, no. 4, pp. 798-805, 2011.

[54] N. Zaman, A. B. Abdullah, and L. T. Jung, "Optimization of energy usage in Wireless Sensor Network using Position Responsive Routing Protocol (PRRP)," in Proceedings of the IEEE Symposium on Computers \& Informatics (ISCI '11), pp. 51-55, Kuala Lumpur, Malaysia, March 2011.

[55] N. Zaman and A. B. Abdullah, "Position Responsive Routing Protocol (PRRP)," in Proceedings of the 13th International Conference on Advanced Communication Technology: Smart Service Innovation through Mobile Interactivity (ICACT '11), pp. 644-648, Seoul, Republic of Korea, February 2011.

[56] N. Zaman, "Energy Optimization through Position Responsive Routing Protocol (PRRP) in wireless sensor network," International Journal of Information and Electronics Engineering, vol. 2, no. 5, pp. 748-751, 2012.

[57] N. Zaman, T. J. Low, and T. Alghamdi, "Energy efficient routing protocol for wireless sensor network," in Proceedings of the 16th International Conference on Advanced Communication Technology (ICACT '14), pp. 808-814, IEEE, Pyeongchang, South Korea, February 2014.

[58] Y. Xu, J. Heidemann, and D. Estrin, "Geography-informed energy conservation for ad hoc routing," in Proceedings of the 7th Annual International Conference on Mobile Computing and Networking (MobiCom '01), pp. 215-222, Rome, Italy, July 2001.

[59] Y. Yu, D. Estrin, and R. Govindan, "Geographical and energy aware routing: a recursive data dissemination protocol for wireless sensor networks," Tech. Rep. UCLA/CSD-TR-01-0023, UCLA Computer Science Department, Los Angeles, Calif, USA, 2001.

[60] B. Chen, K. Jamieson, H. Balakrishnan, and R. Morris, "Span: an energy-efficient coordination algorithm for topology maintenance in Ad Hoc wireless networks," in Proceedings of the 7th ACM International Conference on Mobile Computing and Networking, pp. 315-322, July 2001. 
[61] I. Stojmenovic and X. Lin, "GEDIR: loop-free location based routing in wireless networks," in Proceedings of the International Conference on Parallel and Distributed Computing and Systems, pp. 109-115, Boston, Mass, USA, November 1999.

[62] F. Kuhn, R. Wattenhofer, and A. Zollinger, "Worst-case optimal and average-case efficient geometric ad-hoc routing," in Proceedings of the 4th ACM International Symposium on Mobile Ad Hoc Networking and Computing (MOBIHOC '03), pp. 267-278, Annapolis, Md, USA, June 2003.

[63] J. Kulik, W. Heinzelman, and H. Balakrishnan, "Negotiationbased protocols for disseminating information in wireless sensor networks," Wireless Networks, vol. 8, no. 2, pp. 169-185, 2002.

[64] C. Intanagonwiwat, R. Govindan, and D. Estrin, "Directed diffusion: a scalable and robust communication paradigm for sensor networks," in Proceednigs of the 6th Annual ACM/IEEE International Conference on Mobile Computing and Networking (MobiCom '00), pp. 93-99, Boston, Mass, USA, August 2000.

[65] C. Intanagonwiwat, R. Govindan, D. Estrin, J. Heidemann, and F. Silva, "Directed diffusion for wireless sensor networking," IEEE/ACM Transactions on Networking, vol. 11, no. 1, pp. 2-16, 2003.

[66] D. Estrin, R. Govindan, J. Heidemann, and S. Kumar, "Next century challenges: scalable coordination in sensor networks," in Proceeding of the 5th Annual ACM/IEEE International Conference on Mobile Computing and Networking (MobiCom '99), pp. 263-270, Seattle, Wash, USA, August 1999.

[67] D. Braginsky and D. Estrin, "Rumor routing algorithm for sensor networks," in Proceedings of the 1st ACM International Workshop on Wireless Sensor Networks and Applications (ACM WSNA '02), pp. 22-31, Atlanta, Ga, USA, October 2002.

[68] C. Schurgers and M. B. Srivastava, "Energy efficient routing in wireless sensor networks," in Proceedings of the Communications for Network-Centric Operations: Creating the Information Force (MILCOM '01), pp. 155-161, McLean, Va, USA, 2001.

[69] S. M. Hedetniemi, S. T. Hedetniemi, and A. L. Liestman, "A survey of gossiping and broadcasting in communication networks," Networks, vol. 18, no. 4, pp. 319-349, 1988.

[70] F. Ye, A. Chen, S. Lu, and L. Zhang, "A scalable solution to minimum cost forwarding in large sensor networks," in Proceedings of the 10th International Conference on Computer Communications and Networks (ICCCN '01), pp. 304-309, Scottsdale, Ariz, USA, October 2001.

[71] Y. Yao and J. Gehrke, "The cougar approach to in-network query processing in sensor networks," SIGMOD Record, vol. 31, no. 3, pp. 9-18, 2002.

[72] M. Chu, H. Haussecker, and F. Zhao, "Scalable informationdriven sensor querying and routing for ad hoc heterogeneous sensor networks," The International Journal of High Performance Computing Applications, vol. 16, no. 3, pp. 293-313, 2002.

[73] N. Sadagopan, B. Krishnamachari, and A. Helmy, "The ACQUIRE mechanism for efficient querying in sensor networks," in Proceedings of the 1st International Workshop on Sensor Network Protocol and Application (SNPA '03), pp. 149155, Anchorage, Alaska, USA, May 2003.

[74] R. C. Shah and J. M. Rabaey, "Energy aware routing for low energy ad hoc sensor networks," in Proceedings of the Wireless Communications and Networking Conference (WCNC '02), pp. 350-355, IEEE, March 2002.

[75] A. Savvides, C.-C. Han, and M. B. Strivastava, "Dynamic finegrained localization in ad-hoc networks of sensors," in Proceedings of the 7th Annual ACM/IEEE International Conference on
Mobile Computing and Networking (MobiCom '01), pp. 166-179, Rome, Italy, July 2001.

[76] D. Niculescu and B. Nath, "DV based positioning in Ad Hoc networks," Telecommunication Systems, vol. 22, no. 1-4, pp. 267280, 2003.

[77] N. Bulusu, J. Heidemann, and D. Estrin, "GPS-less low-cost outdoor localization for very small devices," IEEE Communications Magazine, vol. 7, no. 5, pp. 28-34, 2000.

[78] S. Mishra and A. Nasipuri, "An adaptive low power reservation based MAC protocol for wireless sensor networks," in Proceedings of the 23rd IEEE International Performance, Computing, and Communications Conference, Conference Proceedings (IPCCC '04), pp. 731-736, April 2004.

[79] N. Bulusu, D. Estrin, L. Girod, and J. Heidemann, "Scalable coordination for wireless sensor networks: self-configuring localization system," in Proceedings of the 6th International Symposium on Communication Theory and Application (ISCTA '01), pp. 75-82, Ambleside, UK, July 2001.

[80] E. Amiri, H. Keshavarz, M. Alizadeh, M. Zamani, and T. Khodadadi, "Energy efficient routing in wireless sensor networks based on fuzzy ant colony optimization," International Journal of Distributed Sensor Networks, vol. 2014, Article ID 768936, 17 pages, 2014.

[81] W. B. Heinzelman, A. P. Chandrakasan, and H. Balakrishnan, "An application-specific protocol architecture for wireless microsensor networks," IEEE Transactions on Wireless Communications, vol. 1, no. 4, pp. 660-670, 2002.

[82] A. Boukerche, X. Cheng, and J. Linus, "A performance evaluation of a novel energy-aware data-centric routing algorithm in wireless sensor networks," Wireless Networks, vol. 11, no. 5, pp. 619-635, 2005. 